\title{
Sleep loss and recovery after administration of drugs related to different arousal systems in rats
}

\author{
T Hajnik, A Tóth, Ö Szalontai, M Pethő, L Détári \\ Department of Physiology and Neurobiology, Eötvös Loránd University, Budapest, Hungary \\ Received: February 15, 2016 \\ Accepted: July 6, 2016
}

\begin{abstract}
Sleep is homeostatically regulated suggesting a restorative function. Sleep deprivation is compensated by an increase in length and intensity of sleep. In this study, suppression of sleep was induced pharmacologically by drugs related to different arousal systems. All drugs caused non-rapid eye movement (NREM) sleep loss followed by different compensatory processes. Apomorphine caused a strong suppression of sleep followed by an intense recovery. In the case of fluoxetine and eserine, recovery of NREM sleep was completed by the end of the light phase due to the biphasic pattern demonstrated for these drugs first in the present experiments. Yohimbine caused a long-lasting suppression of NREM sleep, indicating that either the noradrenergic system has the utmost strength among the examined systems, or that restorative functions occurring normally during NREM sleep were not blocked. Arousal systems are involved in the regulation of various wakefulness-related functions, such as locomotion and food intake. Therefore, it can be hypothesized that activation of the different systems results in qualitatively different waking states which might affect subsequent sleep differently. These differences might give some insight into the homeostatic function of sleep in which the dopaminergic and noradrenergic systems may play a more important role than previously suggested.
\end{abstract}

Keywords: delta homeostasis, freely moving rats, homeostatic sleep regulation, pharmacological sleep deprivation, recovery sleep, sleep rebound

\section{Introduction}

Wakefulness (W) is a complex behavioral state in which subjects are highly responsive to environmental stimuli. In the mammalian brain, multiple $\mathrm{W}$-promoting cell groups have been identified forming arousal pathways that provide widespread innervation to the forebrain. The concept of ascending reticular activating system (ARAS) (53) was the first to describe the arousal-promoting areas in the brainstem. Components of the ARAS were neurochemically specified as fibers originating from the noradrenergic (NAergic) locus coeruleus (LC), the serotonergic (5-HTergic) raphe nuclei $(\mathrm{RN})$, the cholinergic (ACh) pedunculopontine tegmental (PPT) and laterodorsal tegmental (LDT) nuclei, the histaminergic (His) tuberomammillary system, the dopaminergic (DA) substantia nigra pars compacta (SNpc), ventral tegmental area (VTA), and the ventral periaqueductal gray matter (vPAG). In the forebrain, further arousing systems have been discovered, among them, the cholinergic cells in the basal forebrain (BF) reviewed by Brown et al. (15).

Decreased and/or modified activity of these arousal-promoting systems enables the appearance of sleep. Its amount and timing is regulated by circadian and homeostatic

Corresponding author: Tünde Hajnik, $\mathrm{PhD}$

Department of Physiology and Neurobiology, Eötvös Loránd University

Pázmány Péter sétány $1 / \mathrm{C}$, Budapest 1117 , Hungary

Phone: +361381 2181; Fax: +361381 2182; E-mail: tunde.hajnik@ttk.elte.hu 
processes. The circadian process facilitates $\mathrm{W}$ at those times of the day when activity and foraging are possible (13). Homeostatic sleep functions are reflected by the severe pathological changes evoked by long-term sleep deprivation (SD) (64). Thus, sleep appears to provide necessary circumstances for some restorative processes to take place.

Circadian and homeostatic processes are closely linked to each other (13). W generates a drive for sleep ("sleep pressure" - SP) that is relieved during sleep that occurs when the environmental circumstances are appropriate (63). Accordingly, SP is high at the beginning of sleep and decreases during sleep (18). Sleep intensity can be quantified by the delta wave activity routinely assessed as EEG delta power below $4 \mathrm{~Hz}$ (14).

During SD, SP accumulates. When SD is over, recovery or rebound sleep (RS) is initiated with increased intensity, reflected in the high EEG delta power, and duration (28). The magnitude of delta power depends on the duration of prior $\mathrm{W}(23,75)$, and may reflect restorative processes in direct connection with sleep function. Therefore, SD provides a mean to get some insight into the homeostatic role of sleep. SD can be performed by various instrumental methods (63), while drugs activating some of the arousal systems can also induce $\mathrm{W}$ and/or eliminate delta activity for various durations. In a more confined interpretation, it is not simply the amount of non-rapid eye movement (NREM) sleep, but the amount of delta waves that is important for the restorative effect of sleep. This hypothesis provides the basis of the concept of slow wave or delta homeostasis (25).

If the presence of delta activity during sleep provides the appropriate circumstances for the restorative processes to occur, then pharmacologically induced loss of sleep and delta activity should also be followed by RS. However, it is also possible that elimination of sleep and delta activity by the activation of a given arousal system does not prevent restorative processes from occurring. In that case, RS will be missing or reduced which might give important clues on the nature of the restorative processes.

Though the $\mathrm{W}$-promoting effect of drugs affecting different arousal systems have been intensively researched, the presence or absence of the RS was often overlooked due to the short recordings. In this study, drugs related to the DAergic, 5-HTergic, NAergic, and cholinergic systems were used to enhance $\mathrm{W}$ and suppress or even deprive sleep. We deliberately selected widely used and well-known drugs, even if their specificity is less well defined. Sleep rebound was followed for $18 \mathrm{~h}$.

\section{Materials and Methods}

\section{Surgical procedure}

Experiments were performed on six male Sprague-Dawley rats weighing between 310 and 440 g. Electrode implantation was carried out under i.p. ketamine $(80 \mathrm{mg} / \mathrm{kg}) / \mathrm{xylazine}$ $(10 \mathrm{mg} / \mathrm{kg}$ ) anesthesia. Rats were placed into a stereotaxic frame (David Kopf, Tujunga, USA), then the skin on the head was opened in the midline and muscles were retracted. To record EEG activity, $1.1 \mathrm{~mm}$ stainless steel screws (Fine Science Tools, North Vancouver, Canada) were placed into burr holes over the frontal ( $\mathrm{Br} 2.0 ; \mathrm{L} \mathrm{2.0)}$ and occipital cortices ( $\mathrm{Br}-4.5 ; \mathrm{L} 2.0)$ on both sides. An additional screw implanted into the bone over the cerebellum was used as reference and ground. To monitor electromyographic (EMG) activity, a pair of $250 \mu \mathrm{m}$ Teflon-insulated stainless steel wires was inserted into the neck musculature. All leads were soldered to a miniature connector prepared from a standard $50 \times 2$ connector strip and the skull was covered with acrylic resin (Cranioplastic cement, Plastic One, 
Roanoke, USA). Recording sessions started after 1-2 weeks of recovery. Experiments were carried out in accordance with the European Communities Council Directive of November 24, 1986 and with the guidelines of the local Animal Care and Use Committee. All efforts were made to minimize the number of animals used and their suffering.

\section{Housing}

Rats were kept in a LD12:12 cycle (lights on at 09:30 h) and were housed in individual cages located in a sound-attenuated room throughout the whole experiment. The cages were prepared from clear Plexiglass cylinders (height: $330 \mathrm{~mm}$, diameter: $300 \mathrm{~mm}$ ). Water and standard laboratory chow were available ad libitum.

Rats were connected to the recording apparatus 2 days before the treatments to allow habituation to the recording situation. Flexible flat cables connected the rats to swivels fixed above the large Plexiglass cylinders during the recordings. Cables were folded to a zigzag shape with a rubber string running in the middle to provide free movements of the rat.

\section{EEG recording}

EEG was recorded between the frontal and occipital electrode pairs on both sides through home-designed headstages based on TLC2264I (Texas Instruments, USA) operational amplifiers built into the male connector. Signals from the both sides were recorded, but the best signal with least artifacts was analyzed.

Signals were amplified $(1,000 \times)$, filtered in two steps $(0.3 \mathrm{~Hz}$ to $1 \mathrm{kHz}$ followed by $0.364 \mathrm{~Hz}$ ), then digitalized at a 12-bit resolution by an analog-to-digital (A/D) converter card (UAM-3216) and stored by a custom-made software for further analysis. The A/D sampling frequency was set to $128 \mathrm{~Hz}$ to yield 512 point in $4 \mathrm{~s}$ in order to facilitate Fast Fourier Transformation (FFT) of the signals. EMG was filtered in the same way for technical reasons. All EEG and EMG data obtained during the recording sessions were stored on hard disk for offline analysis.

\section{Treatments}

Drug administration was carried out at the beginning of the light phase (LP). After the injections, recording sessions started immediately and lasted for $18 \mathrm{~h}$. Six rats were recorded simultaneously. Each rat received all treatments and the vehicle in random order. At least 3 days elapsed between subsequent injections in the same rat.

The effects of four drugs were tested in doses as follows: the non-selective DA receptor agonist apomorphine ( $1 \mathrm{mg} / \mathrm{kg}$ corresponding to $3.2 \mu \mathrm{mol} / \mathrm{kg}$ ), the selective 5-HT reuptake inhibitor (SSRI) fluoxetine (10 mg/kg corresponding to $25 \mu \mathrm{mol} / \mathrm{kg}$ ), the adrenergic alpha-2 inhibitory autoreceptor antagonist yohimbine ( $2 \mathrm{mg} / \mathrm{kg}$ corresponding to $5 \mu \mathrm{mol} / \mathrm{kg}$ ), and the acetylcholinesterase (AChE) inhibitor eserine $(0.2 \mathrm{mg} / \mathrm{kg}$ corresponding to $0.7 \mu \mathrm{mol} / \mathrm{kg})$. All drugs were dissolved in $0.4 \%$ methyl cellulose (Methocel F4M, Dow Chemical Company, USA) as vehicle. Drug doses were selected on the basis of previous literature data $(49,58,72)$.

Solutions were freshly prepared before the recording sessions. Drugs were administered intraperitoneally (i.p.) except for apomorphine that was injected subcutaneously (s.c.) complying with the instructions of the supplier. Administered volumes were kept between 1.0 and $1.2 \mathrm{ml}$ in the case of i.p. injections, and between 0.14 and $0.18 \mathrm{ml}$ in the case of s.c. injections depending on the actual weight of the rat. Each rat received all drug treatments and a separate control (vehicle) injection in a randomized fashion. When all recordings were completed, the animals were sacrificed by an i.p. overdose of urethane. 
Data analysis

Sleep scoring. Sleep stages were scored using custom-made semi-automatic software. Power spectra were calculated using the FFT algorithm for all consecutive 4-s periods from all recordings. Power was integrated in the delta $(0.5-4.0 \mathrm{~Hz})$, theta $(4.0-9.0 \mathrm{~Hz})$, alpha $(9.0-$ $14.0 \mathrm{~Hz})$, and beta $(14.0-48.0 \mathrm{~Hz})$ frequency ranges and the ratio of the theta/delta power was determined. EMG data were also processed using the FFT method and the total power (variance) was calculated in the $5.0-48.0 \mathrm{~Hz}$ range.

Epochs containing movement artifacts (high delta power and high EMG variance) and rapid eye movement (REM) sleep epochs (low delta power, high theta/delta ratio, and low muscle tone) were manually removed in all recordings by visual inspection of the EEG and EMG signals.

There are several scoring methods to distinguish NREM sleep and W, either automatic, based on the calculation of sophisticated variables from the recorded data (65), or manually, relying on the decision of an experienced scorer visually inspecting the EEG, EMG, and power curves (55). In all cases, slow wave $(<4 \mathrm{~Hz})$ content of the EEG and the level of EMG activity are the most important indicators used as delta power changes that are closely and inversely related with the level of cortical arousal (79).

In the present experiments, delta power and EMG thresholds were set individually for each rat by visually inspecting the raw EEG and EMG data from control recordings. These objective thresholds were then used to score recordings obtained after the treatments. Epochs in which delta power was above and EMG value below these thresholds, respectively, were marked as NREM sleep, while epochs with lower delta power or higher EMG activity as W.

In most animal experiments, only W, NREM, and REM sleep epochs are distinguished [i.e., $(54,57)]$. In the present experiments, we further divided $\mathrm{W}$ into active wakefulness (AW) and quiet wakefulness (QW), and NREM into light sleep (LS) and deep sleep (DS) based on the delta power values (77). Our intention by scoring recorded epochs into five categories instead of three was to provide a finer frame for analyzing the level of cortical activation within W and NREM sleep following pharmacologically evoked SD. Scoring of $\mathrm{S}-\mathrm{W}$ epochs into four or five categories has been used by various automated scoring systems $(67,83)$ and in several other laboratories $(12,63)$. Raw hypnograms were smoothed, i.e., every 32-s period was assigned to the dominant S-W stage (26).

Analysis of rebound sleep. To examine the effect of the applied drugs on sleep and the following rebound, lengths of S-W stages were analyzed in four overlapping periods starting immediately after drug administration. Sleep delta power was also calculated in the same four periods. As drug effects were expected to be the most pronounced in the first $2 \mathrm{~h}$, this period was analyzed separately ("deprivation period," hours 1-2). As drug administration was carried out at the beginning of the LP, characterized by a dominance of sleep over W, ceasing of drug effects led to an immediate rebound in most cases. To assess the success of this early rebound, the first $4 \mathrm{~h}$ (hours 1-4) were analyzed together as "initial period." In most cases, the first, intense rebound was not able to completely compensate for the lost sleep and delta power. To get a better picture about the long-term recovery process, S-W stages and delta power were followed to the end of the LP (hours 1-12), and through the first $6 \mathrm{~h}$ of the dark phase (DP): "total recording time" (hours 1-18).

Integrated delta power increases during RS either because of more frequent sleep epochs or because of more intense sleep (higher delta power) within the epochs. To distinguish between these two possibilities, delta intensity was calculated at a resolution of $1 \mathrm{~h}$ (sleep delta power/total length of sleep epochs in the given hour). 
Statistical analysis. The extent of recovery in S-W stages was statistically tested in the four periods defined above starting immediately after drug administration. As these periods were not independent, repeated-measures analysis of variance (ANOVA) was calculated separately for each period: hours 1-2 (deprivation period), hours 1-4 (initial period), hours 1-12 (LP), and hours 1-18 (total recording time). ANOVA was followed by post-hoc tests of Dunnett. Significance of delta intensity changes was analyzed by the two-way mixed-design ANOVA method (split-plot) with time and treatment as factors, followed by post-hoc tests of StudentNewman-Keuls. All tests were two-tailed and $p<0.05$ was accepted as the lowest limit of significant difference. Data are shown as mean \pm SEM on figures. Data were plotted in Microcal Origin (OriginLab Corporation, Northampton, USA). Final editing was performed using Adobe Photoshop CS2.

\section{Results}

\section{Deprivation period - NREM}

Drug injections were performed at the beginning of the LP, when sleep dominates. The injection procedure caused transient, non-specific arousal in all rats, even in controls, increasing $\mathrm{W}$ and decreasing NREM sleep.

Following treatment with vehicle only, the amount of delta power peaked in hours 1-2 and in parallel, DS occupied more than half of hour 2 (Fig. 1). During the LP, delta power decreased continuously with a visible drop around the light-dark transition after which it had a stable level. DS changed in parallel, falling below $10 \%$ of time after the light-dark transition, and remaining at this level for the rest of the recording. In contrast, the total amount of LS increased continuously during the LP reaching its peak during the second part of this period, to decrease to a low level, slightly above $10 \%$, at the light-dark transition and staying at this level during the DP. It means that the total amount of NREM sleep (LS + DS) was more or less constant during most of the LP, but there was a shift from high delta power DS to the more superficial, lower delta power LS level (data not shown).

Injection of drugs enhancing the effect of the arousal systems strongly increased $\mathrm{W}$ and inhibited delta power as well as sleep in the initial period (Fig. 2), as expected. Dividing W and NREM sleep into two categories based on delta power, i.e., into AW, QW and LS, DS, respectively, allowed a finer analysis of changes.

Of the drugs tested, apomorphine had the strongest EEG and sleep effects. In the first $1.5 \mathrm{~h}$ (i.e., during most of the deprivation period), delta power dropped to a very low level that had no match following any drug treatments in any time period (Fig. 3a). It was also much lower than the delta power in control recordings during the DP. Accordingly, both DS and LS decreased (Fig. 2). In five of the six rats tested, DS was completely suppressed in this period. Apomorphine caused the largest increment in AW, though QW was almost unchanged (Fig. 2).

Fluoxetine caused similar, but weaker changes in the EEG and in the distribution of S-W stages (Figs 2 and $3 b$ ) than apomorphine. DS was completely missing in four of the six rats in the first post-injection hour, but LS was unchanged. Fluoxetine increased both AW and QW.

Yohimbine had a similar inhibiting effect on delta power as fluoxetine (Fig. $3 b$ and c). DS was suppressed, but LS was unaffected in the first two post-injection hours (Fig. 2). Both AW and QW increased. 


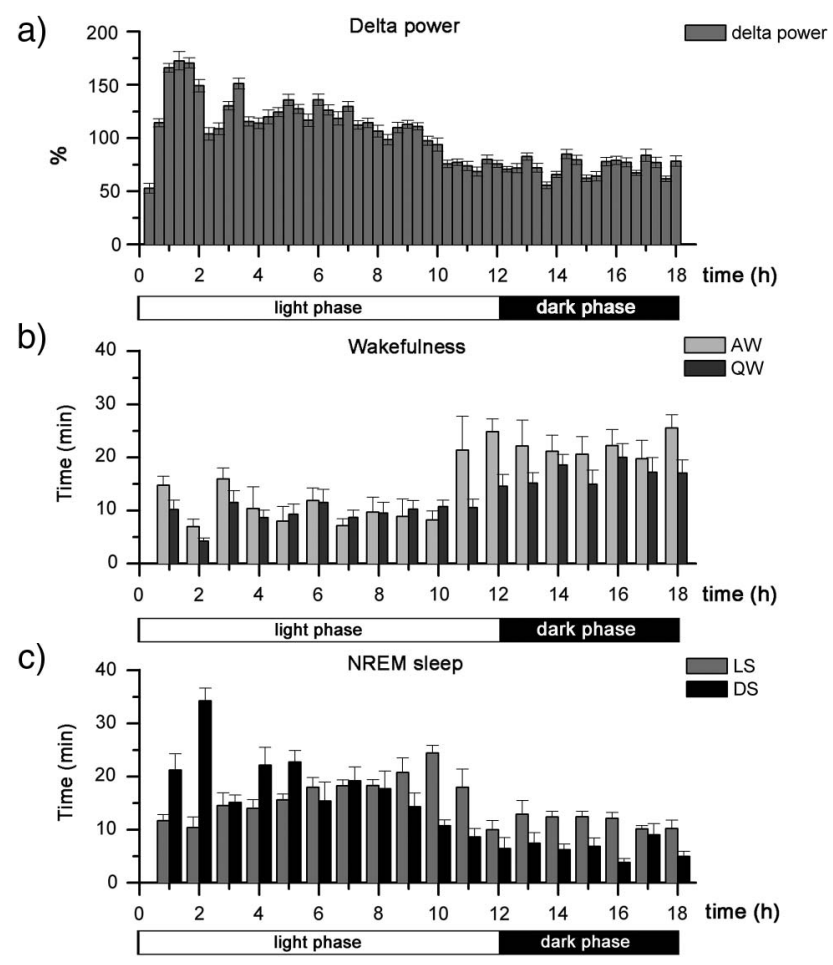

Fig. 1. Time course of delta power (1-4 Hz) values and sleep-wake stages during the 18-h total recording period following vehicle ( $0.4 \%$ methyl cellulose) injections given at the beginning of the light phase $(n=6)$. (a) Changes in the delta power values at a resolution of $20 \mathrm{~min}$ expressed as percent of the whole-day (18 h) average (100\%); (b) wakefulness; (c) NREM sleep. In case of (b) and (c), resolution is $1 \mathrm{~h}$.

Distinction of wakefulness into active (AW) and quiet (QW) wakefulness and NREM sleep into light (LS) and deep (DS) sleep enabled a finer analysis of these states. Data are expressed as mean \pm SEM

Eserine had the weakest effect on EEG among the four drugs. Delta power was only inhibited in the first hour to rise in the second hour to the same level that was seen in the first hour of control recordings. It gave the impression as if the control curve had been shifted to the right by $1 \mathrm{~h}$ after eserine administration (Fig. 3d). Consequently, there was only a small decrease in DS, while LS was unchanged, and QW was slightly increased in the deprivation period (1-2 h, Fig. 2).

\section{Deprivation period - REM}

Apomorphine and fluoxetine completely eliminated REM sleep in the first hour in all six rats recorded. Both drugs caused near-complete REM suppression in the second hour as well (Fig. 2). An even stronger REM suppression was seen following yohimbine treatment: REM sleep was completely abolished in all six rats in the first $2 \mathrm{~h}$ (Fig. 2). Eserine abolished REM sleep in four of the six rats in the first hour; however, no changes were seen in the second hour. Consequently, there was only a slight, non-significant decrease in this phase during the deprivation period.

\section{Recovery - NREM}

Following apomorphine, fluoxetine, and yohimbine treatments, significant delta power and sleep loss appeared by the end of the deprivation period (hours 1-2). If sleep occurred, it was characterized by a low delta power level, thus scored as LS. Therefore, with the exception of apomorphine, the total length of LS did not change. Rebound started after drug effects ceased, but by the end of the initial period (hours 1-4), the total sleep time (LS + DS) was still below and wake time (AW + QW) was above the control value (Fig. 2). However, by the end 
Sleep loss and recovery after arousal system drugs

Apomorphine

(1 mg/kg; s.c.)

AW

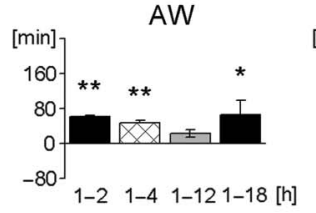

QW

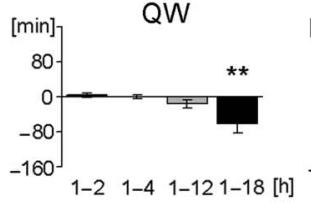

LS

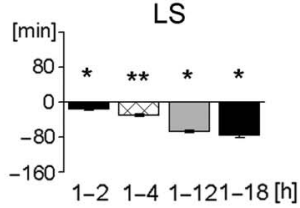

DS

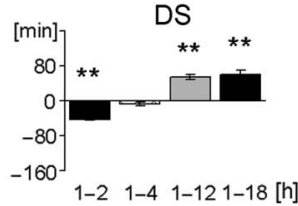

REM

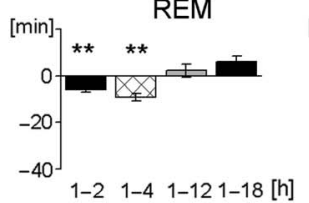

Fluoxetine

(10 mg/kg; i.p.)

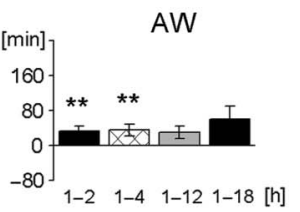

QW

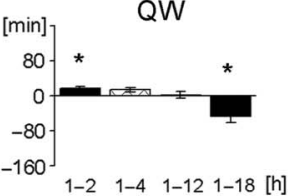

LS

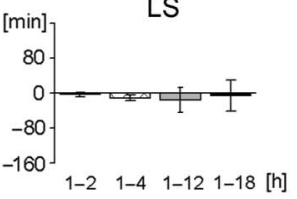

DS

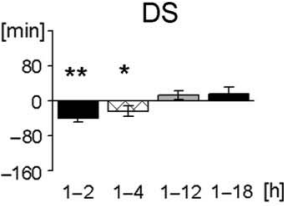

REM

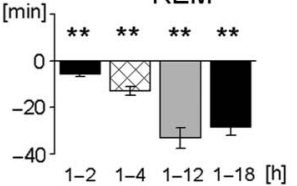

Yohimbine

(2 mg/kg; i.p.)
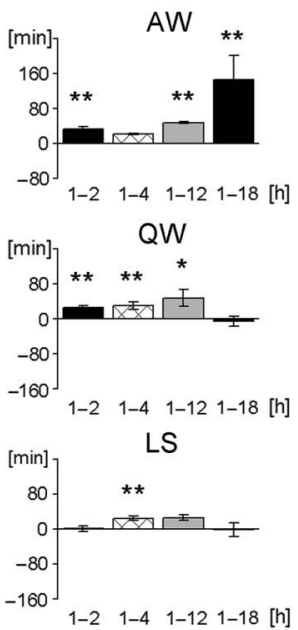

DS

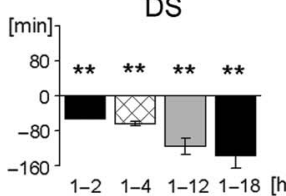

REM

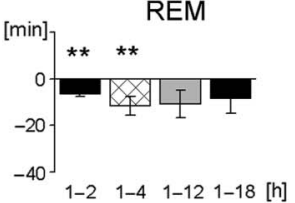

Eserine

(0.2 mg/kg; i.p.)

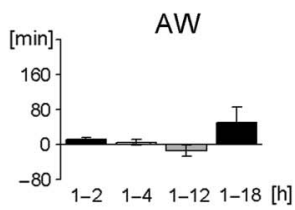

QW

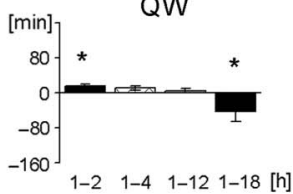

LS

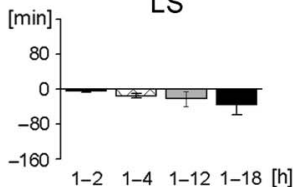

DS

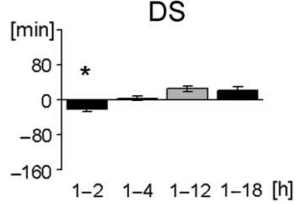

REM

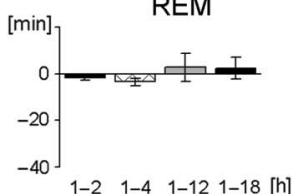

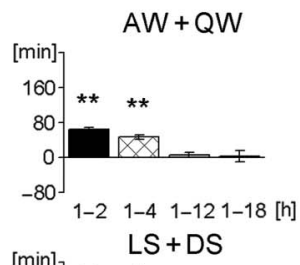
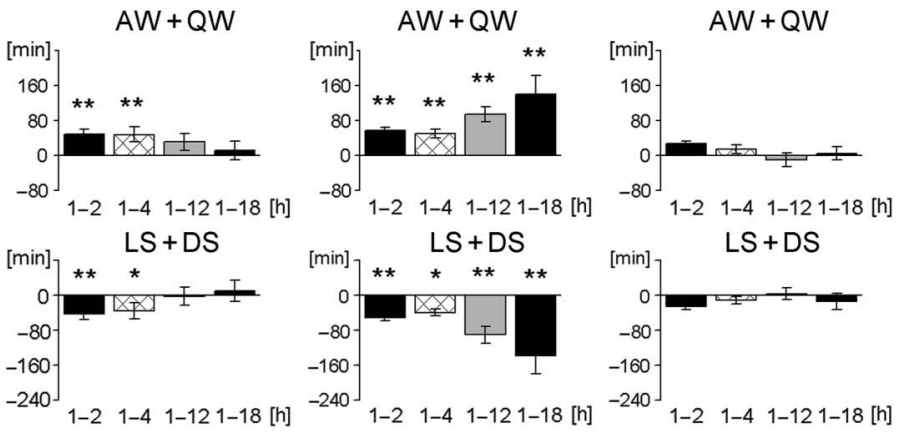

Fig. 2. Changes in the duration of sleep-wake stages compared to the control (vehicle only) values following treatments with apomorphine $(1 \mathrm{mg} / \mathrm{kg}$, i.e., $3.2 \mu \mathrm{mol} / \mathrm{kg})$, fluoxetine $(10 \mathrm{mg} / \mathrm{kg}$, i.e., $25 \mu \mathrm{mol} / \mathrm{kg})$, yohimbine $(2 \mathrm{mg} / \mathrm{kg}$, i.e., $5 \mu \mathrm{mol} / \mathrm{kg})$, and eserine $(0.2 \mathrm{mg} / \mathrm{kg}$, i.e., $0.7 \mu \mathrm{mol} / \mathrm{kg})(n=6)$. Data were separately analyzed in overlapping time periods by repeated-measures ANOVA followed by post-hoc tests of Dunnett. Significance levels: $* p<0.05 ; * * p<0.01$. Data are expressed as mean $\pm \mathrm{SEM}$ 

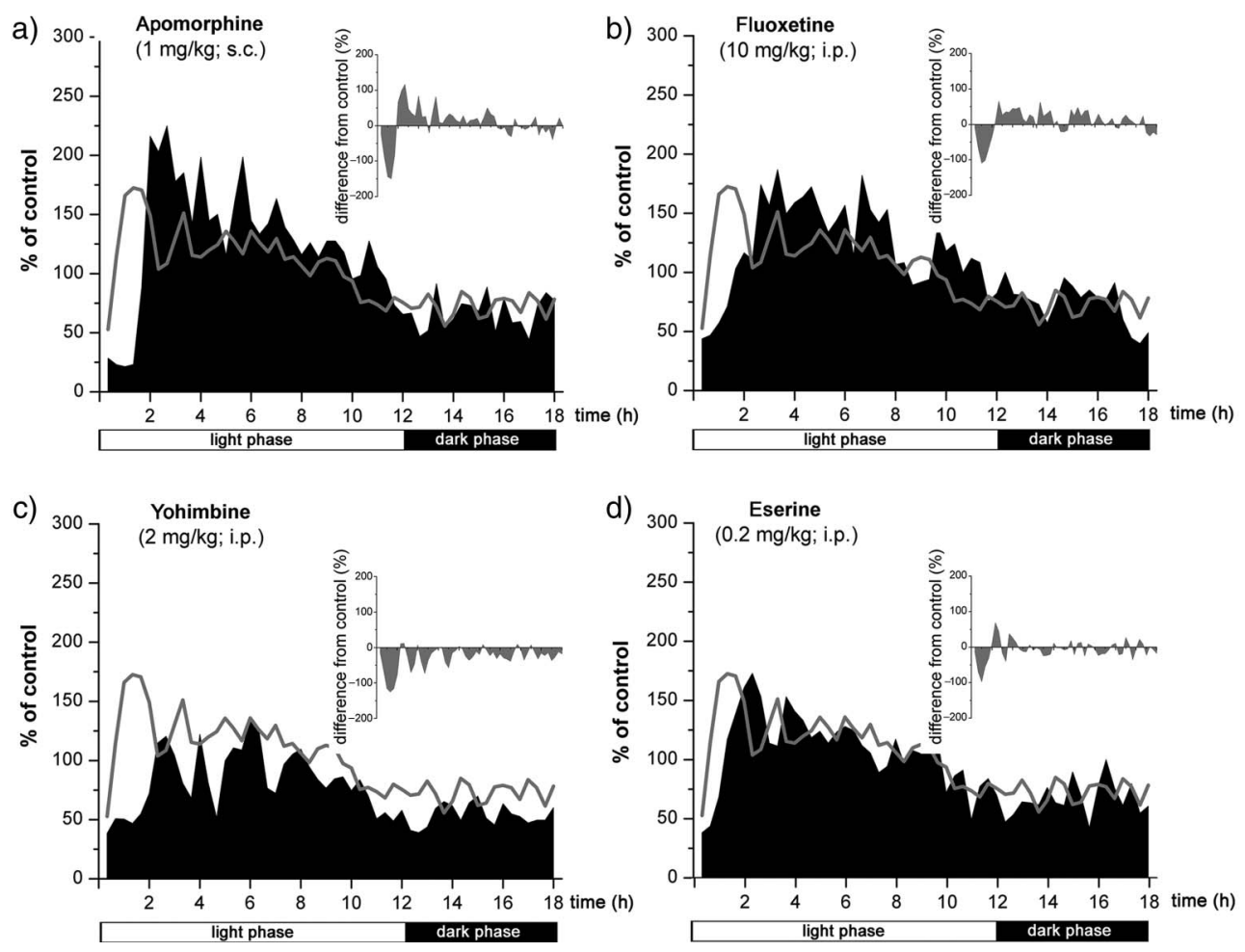

Fig. 3. Time course of delta power after the different treatments at a resolution of $20 \mathrm{~min}$. (a) Apomorphine, (b) fluoxetine, (c) yohimbine, and (d) eserine. The black areas indicate delta power after treatments, while the control values are shown by the gray line. Delta power was normalized by the mean value in the whole control recording for each rat. The insets in the figures depict the difference of delta power after drug administration and during the control recording

of the LP, sleep time was completely recovered in the case of apomorphine and fluoxetine treatment, but not after yohimbine treatment. In contrast to these strong effects, eserine in the applied dose had short-lasting effects only, and sleep was fully recovered by the end of the initial period (Fig. 2).

Apomorphine. Delta power and DS were strongly depressed in the first three-quarter of the deprivation period following apomorphine treatment. However, around the middle of hour 2, there was a sudden, steep increase in delta power peaking above the highest control values. Delta power exceeded the control level for the whole LP (Fig. 3a). Therefore, DS was recovered by the end of the initial period (hours $1-4$ ), and it exceeded the control value by the end of the LP (Fig. 2). In the DP, delta power returned to the control level and the extra DS gained in the LP did not change any further. The loss in LS was never recovered. LS loss compensated for the extra DS, thus total NREM (LS + DS) did not differ from the control in the LP or in the total recording time (Fig. 2).

The very strong rebound of delta power and sleep was caused not only by the increase in the total time spent in NREM sleep, but also by a strong increase in the delta power intensity in sleep epochs (Fig. 4a). Delta power intensity (i.e., integrated power in the delta range for a given unit of NREM sleep time) was elevated practically during the whole recording between hours 3 and 18, strongly exceeding the level of significance between hours 3 and 6 . 
a)

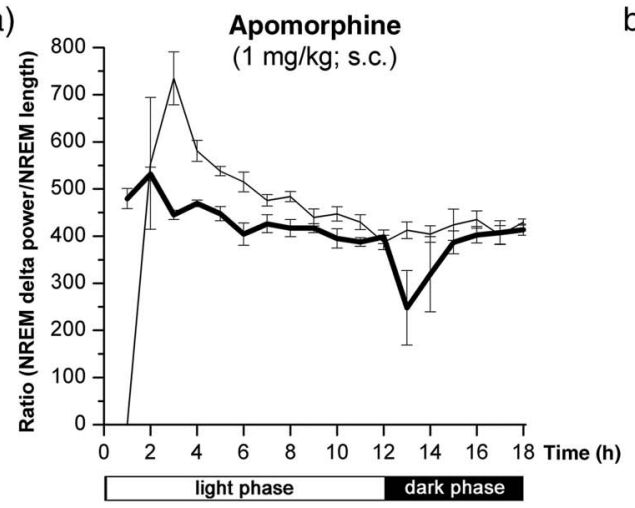

c)

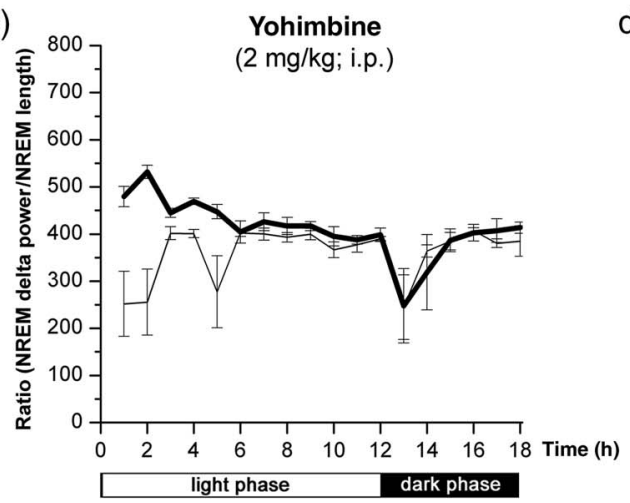

b)

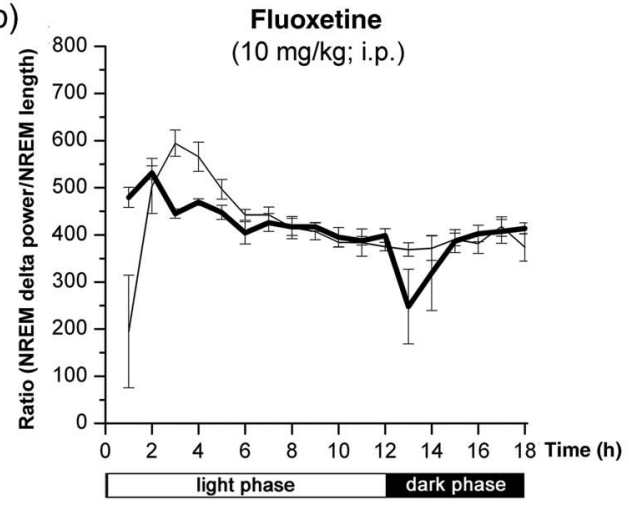

d)

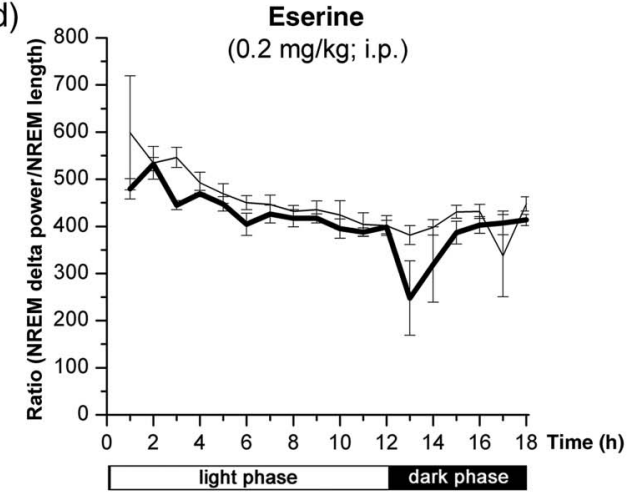

Fig. 4. Delta power intensity following the different treatments. (a) Apomorphine, (b) fluoxetine, (c) yohimbine, and (d) eserine. To assess whether intensity of sleep as reflected in delta power was changed by the treatments, normalized delta power in NREM sleep (LS + DS) was divided by the total length of these stages at a resolution of $1 \mathrm{~h}$. On all four panels, thick black lines show same control values obtained after vehicle injections. Data are expressed as mean \pm SEM

In parallel with the recovery of NREM sleep, W was also restored by the end of the LP, and only a small, not significant excess of AW and loss of QW remained. However, during the DP, AW was strongly above and QW below the control level, resulting in a significant shift toward the lower delta levels during $\mathrm{W}$ for the whole recording time. It was just the opposite of changes seen in LS and DS (Fig. 2).

Fluoxetine. Following fluoxetine treatment, delta power started to increase toward the end of the first hour, and reached its maximum by hour 3 (Fig. 3b). In contrast to apomorphine, however, the peak did not exceed the highest control level. In parallel with the increase of delta power, sleep was also recovered with only a small amount of sleep loss remaining by the end of the initial period (hours 1-4). NREM recovery was complete by the end of the LP (Fig. 2). No further changes occurred in the DP.

Delta power intensity decreased during the deprivation period and increased in parallel with the time spent in DS during recovery. Thus, not only the total sleep time increased, but more delta power was measured in a given unit time of NREM sleep. However, the 
enhancement of delta power intensity was much more moderate and lasted for a shorter time compared to apomorphine treatment (Fig. 4a and b).

In contrast to sleep, extra time gained in AW during the initial period was not compensated in the LP, though the total length of QW by the end of this period did not differ from the control (Fig. 2). Then during the DP, a considerable shift was seen toward the lower delta power values during wakefulness resulting in more AW and less QW, while NREM did not change (Fig. 2). This pattern was similar to that seen after apomorphine treatment.

Yohimbine. Yohimbine caused a long-lasting suppression of delta power that was also seen in the DP (Fig. 3c). Therefore, no real rebound occurred, though the time spent in LS increased compared to the control in hours 3-4 causing significantly higher total LS by the end of the initial period (1-4 h, Fig. 2). By the end of the recording, a total DS loss of more than $2 \mathrm{~h}$ was seen, while LS did not differ from the control, attesting a strong shift toward the lower delta power values during sleep (Fig. 3c).

Delta power decreased not only because less time was spent in NREM sleep, but also because delta power intensity during NREM sleep was also depressed for the whole LP, though it was only significant in the initial period (Fig. 4c).

Corresponding changes were observed in wakefulness. The extra time gained in both AW and QW during the deprivation period (hours 1-2) was slightly augmented further by the end of the LP. Then, in the DP, a strong AW dominance over QW appeared, i.e., a strong shift toward the lower delta power values. QW dropped back to the control level, while AW sharply increased (Fig. 2).

Eserine. The mildest effect was caused by the eserine treatment. It seemed as if the delta power curve had been shifted to the right by $1 \mathrm{~h}$ (Fig. 3d). Recovery of sleep and wakefulness was complete by the end of the initial period (hours 1-4); none of the S-W stages differed significantly from the control by the end of this period (Fig. 2). Interestingly, during the DP, a shift toward the lower delta power values during wakefulness (more AW and less QW) occurred, similar to the aftereffects of apomorphine and fluoxetine treatments (Fig. 2), but it only reached the level of significance for QW. No further changes were seen in NREM; the slight, non-significant excess of DS over LS gained by the end of the LP remained.

Similarly to the S-W stages, delta power intensity differed only slightly from the control (Fig. 4d). The only significant difference was detected in hour 3. The shape of the curve strengthened the impression that the drug only shifted the phase of the $\mathrm{S}-\mathrm{W}$ cycle by $1 \mathrm{~h}$ to the right, and did not have too much other effect.

\section{Recovery - REM}

All drugs suppressed REM sleep in the deprivation period (hours 1-2) and during the total initial period (hours 1-4), though to a different extent (Fig. 2).

Apomorphine caused considerable loss in REM sleep by the end of the initial period (hours 1-4), but by the end of the LP, recovery was complete (Fig. 2).

Fluoxetine produced the strongest suppression of REM sleep, almost completely blocking this sleep epoch for $5 \mathrm{~h}$. The loss of REM increased continuously during the LP reaching about $0.5 \mathrm{~h}$ by the end of the period (Fig. 2). Some recovery was seen during the DP, but at the end of the recording, the loss was still close to $0.5 \mathrm{~h}$ that is about $56 \%$ of the control value.

Yohimbine caused the second strongest REM loss reaching more than 10 min by the end of the initial period (hours 1-4). The loss was not recovered by the end of the LP, 
it diminished only slightly, though at this point, decrease in the total length of REM sleep did not reach the level of statistical significance. The slow recovery continued in the DP, but at the end of the recording, the loss was still around 8 min (Fig. 2).

Eserine had only a mild, non-significant effect on REM sleep that was fully recovered by the end of the LP (Fig. 2).

\section{Discussion}

Drug-induced wake periods might be qualitatively different depending on the drug In this study, W was evoked pharmacologically through the activation of one of the four different arousal systems (DAergic, 5-HTergic, NAergic, and cholinergic) examined. In addition to inducing cortical activation and $\mathrm{W}$, these systems are involved in the regulation of various physiological functions that are closely related to $\mathrm{W}$, such as stress, sexual behavior, locomotion, food intake, and to name a few. Therefore, it can be hypothesized that the activation of the different arousal systems results in qualitatively different $\mathrm{W}$ states.

The function of sleep is not known, but shows homeostatic regulation that suggests it has a restorative function. SD by gentle handling prevents restoration processes occurring during sleep, thus during RS, delta power increases reflecting increased sleep intensity (14). The qualitatively different $\mathrm{W}$ states induced by pharmacological means might affect restoration differently, leading to specific delta power and sleep patterns during recovery. These differences might give some insight into the homeostatic function of sleep.

Apomorphine. DAergic cell groups are located in the midbrain SNpc in the VTA (90), and in the vPAG (47). Projections from these regions run mostly to the dorsal and ventral basal ganglia and to the prefrontal cortex (2). DA acts on five G protein-coupled receptors $\left(\mathrm{D}_{1}-\mathrm{D}_{5}\right)(8)$.

The importance of the DAergic system in sleep regulation is controversial. Identified DAergic VTA neurons showed slow and tonic firing during W and NREM sleep with loose coupling to the actual S-W stage, while prominent burst firing, known to be associated with increased DA release, was observed during REM sleep (21). On the other hand, behaviorally active $\mathrm{W}$ was associated with increased forebrain DA release and drugs that stimulate DA release (cocaine or amphetamine) enhanced arousal (56). In accordance with that, Parkinson's disease is associated with an extensive loss of DAergic cells and increased sleepiness (1), and selective lesion of vPAG DAergic cells resulted in a marked reduction of W (47).

Apomorphine binds non-selectively to all DA receptor types (3) and is a full agonist on $D_{1}$ and $D_{5}$ receptors and a partial agonist on $D_{2}-D_{4}$ receptors (35). In addition, it has a complex receptor binding profile involving non-DA receptors, acting as an antagonist on 5-HT, $\alpha_{1}$-adrenergic, and $\alpha_{2}$-adrenergic receptors (51). Thus, apomorphine binding to non-DA receptors may also be involved in the observed S-W effects.

In the present experiments, administration of apomorphine resulted in continuous active $\mathrm{W}$ for $1.5 \mathrm{~h}$ (Fig. 2), which is in accordance with previous data (44). Apomorphine concentration in the brain peaks $10 \mathrm{~min}$ after administration, declining thereafter with a half-life of about $10 \mathrm{~min}$ (11). This fast elimination can explain the strong and short-lasting wake-inducing effect. Afterward, delta power and DS were significantly increased for the whole LP leading to an overcompensation of DS and a loss in LS. REM sleep was strongly inhibited for $3 \mathrm{~h}$, but was fully recovered by the end of LP (Fig. 2). 
Among the DA receptors, $\mathrm{D}_{1}$ and $\mathrm{D}_{2}$ subtypes play a pivotal role in the $\mathrm{S}-\mathrm{W}$ effects of apomorphine (60). $\mathrm{D}_{1}$ receptor activation excited corticopetal BF neurons and cortical ACh release increased after apomorphine administration (22). $\mathrm{D}_{2}$ receptors are located both presynaptically and postsynaptically and are also functioning as autoreceptors (27). Activation of presynaptic $\mathrm{D}_{2}$ receptors decreased, while postsynaptic $\mathrm{D}_{2}$ receptor activation increased W (38). Autoreceptor-preferring agonists decreased W (7). Taken together, activation of $D_{1}$ receptors and postsynaptic $D_{2}$ receptors might have played a role in apomorphine effects in this study.

In a previous study (32), we have shown that during RS following SD, delta power increased mainly due to the increased occurrence of down or inactive states. These states were always preceded by an increased activity in the cortical neurons giving the impression that during sleep, the cells were more sensitive to activation and responded with hyperpolarization, i.e., with down states. In the present experiments, it was not only the amount of DS that increased after apomorphine effect ceased, but also the delta intensity during sleep (Fig. 4a). DA is critically involved in highly aroused and highly motivated states (24). It can be hypothesized that increased activity in these circuits caused by apomorphine led to higher susceptibility of neurons toward activation during RS and that this factor led to the increased delta power and delta intensity that was stronger than what was needed to recover lost sleep. Fluoxetine. 5-HTergic neurons are located in and close to the midline throughout the brainstem and are divided into several nuclei. The cells provide a widespread innervation to practically all areas of the central nervous system (85). The effects of 5-HT are mediated by seven different receptor types known to date $\left(5-\mathrm{HT}_{1}-5-\mathrm{HT}_{7}\right)(37)$.

5-HT participates in several functions including cognition, affection, food intake (40), and promotes $\mathrm{W}$ and inhibits REM sleep (80). Systemic injection of various selective agonists of either the $\mathrm{G}_{\mathrm{i}}$ protein-coupled $5-\mathrm{HT}_{1}$ or the $\mathrm{G}_{\mathrm{q}}$ protein-coupled $5-\mathrm{HT}_{2}$ or the ionotropic $5-\mathrm{HT}_{3}$ type receptors similarly increased $\mathrm{W}$ and reduced $\mathrm{NREM}$ and REM sleep in the rat [reviewed in (52)].

Most of the 5-HTergic innervation of brain regions involved in S-W regulation originates from the dorsal raphe nucleus (DRN) (40). The firing rate of DRN neurons decreases during NREM sleep relative to $\mathrm{W}$ and firing virtually ceases during REM sleep (48).

Based on the above-mentioned findings, it is reasonable to expect that acute administration of SSRIs, prolonging 5-HT effect in 5-HTergic synapses (19), increases W and decreases NREM and REM sleep. Indeed, the most consistent effect of SSRIs is REM sleep suppression (73). However, the effect of SSRIs on NREM sleep and W is ambiguous. Acute administration of some SSRIs caused a biphasic effect. Zimeldine (81) and alaproclate (82) first increased W, but this was followed by an increase in NREM sleep. No such effect was shown for fluoxetine yet. Thus, for the first time, our present results demonstrate the biphasic effect of fluoxetine in rats. The pattern was similar to that seen after apomorphine, except that a smaller rebound occurred after the initial inhibition of slow waves and DS (Fig. 3b). The same applies for delta intensity that was elevated for $5 \mathrm{~h}$ with an onset in the third hour (Fig. 4b).

In contrast to apomorphine, fluoxetine has a slow degradation rate with an elimination half-life of $5 \mathrm{~h}$ (17). The only active metabolite of fluoxetine, norfluoxetine has an even longer elimination half-life of $15 \mathrm{~h}$ (17) and elevates 5-HT level in the cortex of rats for as long as $18 \mathrm{~h}$ (61). Therefore, fluoxetine treatment might have increased 5-HT levels for the whole recording period in our experiments. This may explain the strong suppression of REM 
sleep during the LP followed by only a weak recovery in the DP (Fig. 2). It is more difficult to find an explanation for the fact that NREM sleep recovery was complete by the end of the LP despite the supposedly high 5-HT level (Fig. 2). Prolonged increase in forebrain extracellular 5-HT levels is known to elicit a negative feedback process involving 5-HT $1 \mathrm{~A}$-type autoreceptors in DRN neurons (4) that decreased 5-HT release, but a similar mechanism was not described in the case of acute SSRI applications. A possible explanation might be the desensitization of other 5-HT receptor subtypes.

Though chronic SSRI treatment is anxiolytic, acute SSRI application might be anxiogenic (30). It was also suggested that W-promoting effect of SSRIs might be secondary (81), as SSRI administration was found to cause behavioral and motor activation (9). Thus, it seems that increased 5-HT levels exert complex effects on systems underlying S-W regulation and on other behavioral systems that interact with $\mathrm{S}-\mathrm{W}$ regulation (80).

Yohimbine. The most important NAergic cell group involved in the S-W regulation is located in the LC from where axons innervate most of the forebrain (42). NA acts through $\alpha 1-, \alpha 2-$, and $\beta$-type receptors, each type containing multiple subtypes (16).

NA is crucial in the maintenance of aroused W. LC neurons fire at moderate frequency during $\mathrm{W}$ while their activity is diminished during NREM sleep and almost non-existent during REM sleep (5). Many NAergic LC neurons increase their firing activity in response to novel stimuli and their discharges precede behavioral responses (69). Both kinds of activations lead to an increased cortical release of NA and the consequent EEG activation (6).

Drugs that either stimulate the release or block the reuptake of NA increase W (10). Systemic administration of excitatory $\alpha_{1}$-adrenoceptor antagonists, like prazosin (58), or agonists of the inhibitory $\alpha_{2}$-adrenoceptors, like guanfacine facilitate sleep (66). By contrast, antagonists of the $\alpha_{2}$-adrenoceptor, such as yohimbine, delay and suppress sleep (58), most likely by blocking the $\alpha_{2}$-type autoreceptors on NAerg neurons and enhancing NA release (68).

In our experiment, yohimbine induced a long-lasting suppression of delta power (Fig. 3c) and DS (Fig. 2). It was obvious not only during the LP, but also in the DP. Not only the total amount of sleep and delta power was below the control value, but delta intensity during NREM sleep as well, at least during the LP (Fig. 4c). These long-lasting effects are in accordance with the pharmacokinetics of yohimbine, which is characterized by rapid distribution followed by a slow elimination with a half-life of 7-8 h (36). The continuous presence of yohimbine in the brain tissue and the consequent increased NA release might have been one of the causes why no recovery of DS could occur during the whole recording time, not even in the DP, though the loss of this sleep stage was the strongest among the applied drugs. The long-lasting increase in NA level might also account for the strong suppression and very weak and delayed recovery of REM sleep (Fig. 2).

Although fluoxetine potentially had an even longer effect, the increase in SP and the putative decrease of synaptic efficacy at 5-HT synapses were sufficient to overcome drug effect. It is difficult to imagine that similar mechanisms were unable to force out recovery in the case of yohimbine. An alternate explanation for the effect of yohimbine might be that SP did not increase significantly, as restorative processes may have occurred even if the EEG was desynchronized and slow waves were blocked. This assumption is also supported by the decrease of delta intensity during NREM (Fig. 4c). These effects may be mediated through $\alpha_{2}$ receptors. Yohimbine equally blocks presynaptic and postsynaptic $\alpha_{2}$ receptors (29). Blockade of autoreceptors increases the activity of NAergic neurons and the release of 
cortical NA (68), but postsynaptic $\alpha_{2}$ receptors are also inhibited leading to disinhibition in the affected cells. The disinhibition could reduce signal-to-noise ratio in the cortex. It was suggested that the main function of NAergic LC neurons is to enhance the efficiency of signal processing by increasing the signal-to-noise ratio in the cortex through reducing the background neuronal activity ("noise") (6). If noise increases due to disinhibition, then it might lead to an increase of cortical activity in the absence of relevant stimuli, and consequently to the decrease of delta activity without influencing the restorative functions of sleep.

Eserine. Cholinergic cells involved in the regulation of $\mathrm{W}$ and cortical arousal are located in the BF and in the mesencephalic PPT and LDT (89). Cholinergic projections from the BF innervate the whole cortical mantle (88), while PPT and LDT project to the brainstem, hypothalamus, thalamus, and the BF (74). ACh exerts its effect mainly through different subtypes of muscarinic receptors (mAChRs). In the rat brain, M1-M4 subtypes have been identified (46), though nicotinic ACh receptors (nAChRs) are also widely distributed in the brain (20).

The firing rate of $\mathrm{BF} A C h$ neurons is highest during $\mathrm{W}$ and REM sleep with a minimal activity during NREM sleep (33). ACh released from cortical projections of the BF closes different $\mathrm{K}^{+}$channels in pyramidal cells via mAChRs (50), thus increasing their excitability (31) and even causing depolarization and excitation (31). Cortical desynchronization can be induced by $\mathrm{mAChR}$ agonists, mimicking behavioral activation related to emotional reactions, attention, and learning while $\mathrm{mAChR}$ antagonists produce EEG slowing and impaired cognition (84). Centrally acting selective AChE inhibitors were found to cause increased $\mathrm{W}$ and a decreased NREM and REM sleep (39).

In our experiments, eserine had a moderate suppressing effect on delta power (Fig. 3d) and DS (Fig. 2) during the deprivation period (hours 1-2). This moderate loss was almost completely recovered already during the initial period (hours 1-4), during which delta intensity was also slightly increased (Fig. 4d). Similar to the case of fluoxetine, this biphasic effect was not reported earlier in the literature, as previous studies focused mostly on the acute $\mathrm{W}$ increase, neglecting the subsequent increase in sleep and delta power. Thus, this study is the first description of such a fast recovery. In addition, eserine seemed to delay the delta power curve by $1 \mathrm{~h}$. Interestingly, this delay was not seen in REM sleep (data not shown).

The main effect of eserine is the enhancement of ACh transmission at all active cholinergic synapses, and probably extrasynaptically as well. The majority of these synaptic effects probably occur via muscarinic receptors, though the role of nicotinic receptors should also be considered as nicotine and $\mathrm{nAChR}$ agonists were found to excite pyramidal neurons in the prefrontal cortex (86).

Similarly to apomorphine, eserine also has a short (20-30 min) elimination half-life in the brain tissue (41). This fast elimination can explain its short-lasting sleep suppression effects.

ACh was implicated in the generation of REM sleep (43) and cholinergic cells are activated during REM sleep (33). Microinjection of the AChE inhibitor neostigmine into the dorsal pontine tegmentum evoked REM sleep in rats (59). After systemic administration of various AChE inhibitors such as eserine (45), increased REM sleep was reported in rats. However, some studies reported decreased REM sleep after systemic injections (70). It was suggested that physostigmine effect on REM sleep depends on the actual S-W stage at the time of the application. Physostigmine can elicit REM sleep when injected during NREM sleep but when injected during W, it evokes a more aroused state with decreased REM sleep 
(71). The present data support this hypothesis as REM sleep slightly decreased after eserine administration in the first $4 \mathrm{~h}$.

Distinct recovery of sleep stages containing different amount of delta waves

In this study, recovery of sleep stages with different levels of delta activity were also analyzed after pharmacologically evoked SD. NREM sleep stages with different amount of delta waves recovered differently after SD. In most cases, loss of the stage with low level of delta activity (i.e., LS) during the initial period was not recovered later. Yohimbine represented an exception to this rule as minimal LS loss in the initial period was recovered later, but this recovery was more related to DS recovery which recovered partly as LS: Moreover, in the case of apomorphine, LS loss continuously increased during the whole recording period. These findings are in agreement with the results of previous studies reaching the conclusion that LS does not seem to be an important feature of RS (62). This phenomenon supports the current hypothesis that the subject of the homeostatic regulation may not be the broadly defined sleep stage but instead the slow delta waves (87). In this conception, delta waves are markers and/or correlates of several important processes which may occur during only deep sleep (e.g., memory consolidation, plastic changes, etc.) and these processes may be linked directly to the function of NREM sleep (76).

\section{REM sleep recovery}

REM sleep strongly depends on NREM sleep as in healthy sleep, the presence of some NREM sleep is a prerequisite for the occurrence of REM sleep. During the sleep-dominated LP, the NREM-REM cycle has a time period of about 12-20 min in rats (78). In this study, all drugs reduced REM sleep in the first $4 \mathrm{~h}$, though this effect was only moderate after eserine treatment (Fig. 2). In the case of apomorphine and eserine, full recovery and even a slight overcompensation was seen by the end of the recording in parallel with changes in DS. This observation might indicate a priming effect of deep NREM sleep in REM sleep generation.

In contrast to apomorphine and eserine, minimal recovery of REM was seen after fluoxetine and yohimbine, though lost DS was recovered after fluoxetine treatment. The two activating systems involved, 5-HTerg and NAerg, are well known to have a minimal activity in REM sleep suggesting a specific inhibitory control over REM generation (34). As both fluoxetine and yohimbine have a long half-life, the lacking recovery of REM sleep was probably due to the long-lasting increase in the 5-HTerg and NAerg transmission.

\section{Concluding remarks}

In this study, suppression of delta activity and increased $\mathrm{W}$ were induced pharmacologically by different drugs related to different arousal systems (DAergic, 5-HTergic, NAergic, and AChergic systems) and recovery was followed for $18 \mathrm{~h}$. In the case of fluoxetine and eserine, recovery of NREM sleep was fast and was completed by the end of the LP due to the biphasic pattern (suppression followed by rebound) first demonstrated for these drugs in the present experiments.

Even more interestingly, apomorphine caused a very strong suppression of delta activity followed by a very intense recovery of delta power and DS that increased above the control level at the expense of LS. Though apomorphine is not completely specific to the DAergic system, the present results may suggest that the DAergic system is more important in S-W regulation and NREM sleep homeostasis than previously suggested and further experiments using more selective drugs for the different DA receptors are justified. 
In a similar vein, the long-lasting delta power and NREM sleep suppression caused by yohimbine might be worth further examination. The fact that delta power and sleep loss increased in the course of the recording might indicate that either the NA system has the utmost strength among the examined activating systems, or that restorative functions occurring normally during NREM sleep were not blocked. Even longer follow-up of the recovery process is needed to find out whether NREM sleep recovery eventually occurs. In addition, selective manipulation of the various NA receptors should be carried out to more precisely characterize the mechanism by which NA influences the regulation of cortical activity and the $\mathrm{S}-\mathrm{W}$ cycle.

\section{Acknowledgement}

The work of L. Détári was supported by Hungarian Scientific Research Fund (OTKA) grant (K 68445).

\section{Conflict of interest}

The authors declare that they have no conflict of interest.

\section{REFERENCES}

1. Adler CH, Thorpy MJ: Sleep issues in Parkinson's disease. Neurology 64 (12 Suppl. 3), S12-S20 (2005)

2. Albanese A, Altavista MC, Rossi P: Organization of central nervous system dopaminergic pathways. J. Neural Transm. Suppl. 22, 3-17 (1986)

3. Aramakis VB, Hsieh CY, Leslie FM, Metherate R: A critical period for nicotine-induced disruption of synaptic development in rat auditory cortex. J. Neurosci. 20(16), 6106-6116 (2000)

4. Artigas F, Romero L, de Montigny C, Blier P: Acceleration of the effect of selected antidepressant drugs in major depression by 5-HT1A antagonists. Trends Neurosci. 19(9), 378-383 (1996)

5. Aston-Jones G, Bloom FE: Activity of norepinephrine-containing locus coeruleus neurons in behaving rats anticipates fluctuations in the sleep-waking cycle. J. Neurosci. 1(8), 876-886 (1981)

6. Aston-Jones G, Cohen JD: An integrative theory of locus coeruleus-norepinephrine function: adaptive gain and optimal performance. Annu. Rev. Neurosci. 28, 403-450 (2005)

7. Bagetta G, Corasaniti MT, Strongoli MC, Sakurada S, Nistico G: Behavioural and ECoG spectrum power effects after intraventricular injection of drugs altering dopaminergic transmission in rats. Neuropharmacology 26(8), 1047-1052 (1987)

8. Beaulieu JM, Gainetdinov RR: The physiology, signaling, and pharmacology of dopamine receptors. Pharmacol. Rev. 63(1), 182-217 (2011)

9. Belzung C, Le Guisquet AM, Barreau S, Calatayud F: An investigation of the mechanisms responsible for acute fluoxetine-induced anxiogenic-like effects in mice. Behav. Pharmacol. 12(3), 151-162 (2001)

10. Berridge CW: Noradrenergic modulation of arousal. Brain Res. Rev. 58(1), 1-17 (2008)

11. Bianchi G, Landi M, Garattini S: Disposition of apomorphine in rat brain areas: relationship to stereotypy. Eur. J. Pharmacol. 131(2-3), 229-236 (1986)

12. Bjorvatn B, Fagerland S, Ursin R: EEG power densities $(0.5-20 \mathrm{~Hz})$ in different sleep-wake stages in rats. Physiol. Behav. 63(3), 413-417 (1998)

13. Borbely AA: A two process model of sleep regulation. Hum. Neurobiol. 1, 195-204 (1982)

14. Borbely AA, Baumann F, Brandeis D, Strauch I, Lehmann D: Sleep deprivation: effect on sleep stages and EEG power density in man. Electroencephalogr. Clin. Neurophysiol. 51(5), $483-495$ (1981)

15. Brown RE, Basheer R, McKenna JT, Strecker RE, McCarley RW: Control of sleep and wakefulness. Physiol. Rev. 92(3), 1087-1187 (2012)

16. Bylund DB, Eikenberg DC, Hieble JP, Langer SZ, Lefkowitz RJ, Minneman KP, Molinoff PB, Ruffolo RR Jr, Trendelenburg U: International Union of Pharmacology nomenclature of adrenoceptors. Pharmacol. Rev. 46(2), 121-136 (1994)

17. Caccia S, Cappi M, Fracasso C, Garattini S: Influence of dose and route of administration on the kinetics of fluoxetine and its metabolite norfluoxetine in the rat. Psychopharmacology (Berl.) 100(4), 509-514 (1990) 
18. Campbell IG, Higgins LM, Darchia N, Feinberg I: Homeostatic behavior of fast Fourier transform power in very low frequency non-rapid eye movement human electroencephalogram. Neuroscience 140(4), 1395-1399 (2006)

19. Celada P, Puig M, Amargos-Bosch M, Adell A, Artigas F: The therapeutic role of 5-HT1A and 5-HT2A receptors in depression. J. Psychiatry Neurosci. 29(4), 252-265 (2004)

20. Clarke PB: Nicotinic receptors in mammalian brain: localization and relation to cholinergic innervation. Prog. Brain Res. 98, 77-83 (1993)

21. Dahan L, Astier B, Vautrelle N, Urbain N, Kocsis B, Chouvet G: Prominent burst firing of dopaminergic neurons in the ventral tegmental area during paradoxical sleep. Neuropsychopharmacology 32(6), 1232-1241 (2007)

22. Day J, Fibiger HC: Dopaminergic regulation of cortical acetylcholine release: effects of dopamine receptor agonists. Neuroscience 54(3), 643-648 (1993)

23. Dijk DJ, Beersma DG, Daan S, Bloem GM, van den Hoofdakker RH: Quantitative analysis of the effects of slow wave sleep deprivation during the first $3 \mathrm{~h}$ of sleep on subsequent EEG power density. Eur. Arch. Psychiatry Neurol. Sci. 236(6), 323-328 (1987)

24. Feenstra MG: Dopamine and noradrenaline release in the prefrontal cortex in relation to unconditioned and conditioned stress and reward. Prog. Brain Res. 126, 133-163 (2000)

25. Feinberg I: Delta homeostasis, stress, and sleep deprivation in the rat: a comment on Rechtschaffen et al. Sleep 22(8), 1021-1030 (1999)

26. Figueroa Helland VC, Gapelyuk A, Suhrbier A, Riedl M, Penzel T, Kurths J, Wessel N: Investigation of an automatic sleep stage classification by means of multiscorer hypnogram. Methods Inf. Med. 49(5), 467-472 (2010)

27. Ford CP: The role of D2-autoreceptors in regulating dopamine neuron activity and transmission. Neuroscience 282, 13-22 (2014)

28. Franken P, Dijk DJ, Tobler I, Borbely AA: Sleep deprivation in rats: effects on EEG power spectra, vigilance states, and cortical temperature. Am. J. Physiol. 261(1 Pt. 2), R198-R208 (1991)

29. Goldberg MR, Robertson D: Yohimbine: a pharmacological probe for study of the alpha 2-adrenoreceptor. Pharmacol. Rev. 35(3), 143-180 (1983)

30. Greenwood BN, Strong PV, Brooks L, Fleshner M: Anxiety-like behaviors produced by acute fluoxetine administration in male Fischer 344 rats are prevented by prior exercise. Psychopharmacology (Berl.) 199(2), 209-222 (2008)

31. Gulledge AT, Bucci DJ, Zhang SS, Matsui M, Yeh HH: M1 receptors mediate cholinergic modulation of excitability in neocortical pyramidal neurons. J. Neurosci. 29(31), 9888-9902 (2009)

32. Hajnik T, Toth A, Detari L: Characteristic changes in the slow cortical waves after a 6-h sleep deprivation in rat. Brain Res. 1501, 1-11 (2013)

33. Hassani OK, Lee MG, Henny P, Jones BE: Discharge profiles of identified GABAergic in comparison to cholinergic and putative glutamatergic basal forebrain neurons across the sleep-wake cycle. J. Neurosci. 29(38), 11828-11840 (2009)

34. Hobson JA, McCarley RW, Wyzinski PW: Sleep cycle oscillation: reciprocal discharge by two brainstem neuronal groups. Science 189(4196), 55-58 (1975)

35. Hsieh GC, Hollingsworth PR, Martino B, Chang R, Terranova MA, O’Neill AB, Lynch JJ, Moreland RB, Donnelly-Roberts DL, Kolasa T, Mikusa JP, McVey JM, Marsh KC, Sullivan JP, Brioni JD: Central mechanisms regulating penile erection in conscious rats: the dopaminergic systems related to the proerectile effect of apomorphine. J. Pharmacol. Exp. Ther. 308(1), 330-338 (2004)

36. Hubbard JW, Pfister SL, Biediger AM, Herzig TC, Keeton TK: The pharmacokinetic properties of yohimbine in the conscious rat. Naunyn Schmiedebergs Arch. Pharmacol. 337(5), 583-587 (1988)

37. Hung AS, Tsui TY, Lam JC, Wai MS, Chan WM, Yew DT: Serotonin and its receptors in the human CNS with new findings - a mini review. Curr. Med. Chem. 18(34), 5281-5288 (2011)

38. Isaac SO, Berridge CW: Wake-promoting actions of dopamine D1 and D2 receptor stimulation. J. Pharmacol. Exp. Ther. 307(1), 386-394 (2003)

39. Ishida T, Obara Y, Kamei C: Studies on wakefulness-promoting effect of memantine in rats. Behav. Brain Res. 206(2), 274-278 (2010)

40. Jacobs BL, Azmitia EC: Structure and function of the brain serotonin system. Physiol. Rev. 72(1), 165-229 (1992)

41. Johansson M, Nordberg A: Pharmacokinetic studies of cholinesterase inhibitors. Acta Neurol. Scand. Suppl. 149, 22-25 (1993)

42. Jones BE, Moore RY: Ascending projections of the locus coeruleus in the rat. II. Autoradiographic study. Brain Res. 127(1), 25-53 (1977) 
43. Jouvet M, Jeannerod M, Delorme F: Organization of the system responsible for phase activity during paradoxical sleep. C. R. Seances Soc. Biol. Fil. 159(7), 1599-1604 (1965)

44. Kafi S, Gaillard JM: Brain dopamine receptors and sleep in the rat: effects of stimulation and blockade. Eur. J. Pharmacol. 38(2), 357-363 (1976)

45. Khazan N, Bar R, Sulman FG: The effect of cholinergic drugs on paradoxical sleep in the rat. Int. J. Neuropharmacol. 6(4), 279-282 (1967)

46. Levey AI, Kitt CA, Simonds WF, Price DL, Brann MR: Identification and localization of muscarinic acetylcholine receptor proteins in brain with subtype-specific antibodies. J. Neurosci. 11(10), 3218-3226 (1991)

47. Lu J, Jhou TC, Saper CB: Identification of wake-active dopaminergic neurons in the ventral periaqueductal gray matter. J. Neurosci. 26(1), 193-202 (2006)

48. McGinty DJ, Harper RM: Dorsal raphe neurons: depression of firing during sleep in cats. Brain Res. 101(3), 569-575 (1976)

49. Mereu GP, Scarnati E, Paglietti E, Quarantotti BP, Chessa P, Di Chiara G, Gessa GL: Sleep induced by low doses of apomorphine in rats. Electroencephalogr. Clin. Neurophysiol. 46(2), 214-219 (1979)

50. Metherate R, Cox CL, Ashe JH: Cellular bases of neocortical activation: modulation of neural oscillations by the nucleus basalis and endogenous acetylcholine. J. Neurosci. 12(12), 4701-4711 (1992)

51. Millan MJ, Maiofiss L, Cussac D, Audinot V, Boutin JA, Newman-Tancredi A: Differential actions of antiparkinson agents at multiple classes of monoaminergic receptor. I. A multivariate analysis of the binding profiles of 14 drugs at 21 native and cloned human receptor subtypes. J. Pharmacol. Exp. Ther. 303(2), 791-804 (2002)

52. Monti JM, Jantos H, Monti D (2008): Serotonin and sleep/wake regulation. In: Neurochemistry of Sleep and Wakefulness, eds Monti JM, Pandi-Perumal SR, Sinton CM, Cambridge University Press, Cambridge, p. xxiv, 482 p.

53. Moruzzi G, Magoun HW: Brain stem reticular formation and activation of the EEG. Electroencephalogr. Clin. Neurophysiol. 1, 455-473 (1949)

54. Murillo-Rodriguez E, Haro R, Palomero-Rivero M, Millan-Aldaco D, Drucker-Colin R: Modafinil enhances extracellular levels of dopamine in the nucleus accumbens and increases wakefulness in rats. Behav. Brain Res. 176(2), 353-357 (2007)

55. Neckelmann D, Olsen OE, Fagerland S, Ursin R: The reliability and functional validity of visual and semiautomatic sleep/wake scoring in the Moll-Wistar rat. Sleep 17(2), 120-131 (1994)

56. Nishino S, Mao J, Sampathkumaran R, Shelton J: Increased dopaminergic transmission mediates the wakepromoting effects of CNS stimulants. Sleep Res. Online 1(1), 49-61 (1998)

57. Ocampo-Garces A, Molina E, Rodriguez A, Vivaldi EA: Homeostasis of REM sleep after total and selective sleep deprivation in the rat. J. Neurophysiol. 84(5), 2699-2702 (2000)

58. Pellejero T, Monti JM, Baglietto J, Jantos H, Pazos S, Cichevski V, Hawkins M: Effects of methoxamine and $\alpha$-adrenoceptor antagonists, prazosin and yohimbine, on the sleep-wake cycle of the rat. Sleep 7(4), 365-372 (1984)

59. Pollock MS, Mistlberger RE: Microinjection of neostigmine into the pontine reticular formation of the mouse: further evaluation of a proposed REM sleep enhancement technique. Brain Res. 1031(2), 253-267 (2005)

60. Qu WM, Huang ZL, Xu XH, Matsumoto N, Urade Y: Dopaminergic D1 and D2 receptors are essential for the arousal effect of modafinil. J. Neurosci. 28(34), 8462-8469 (2008)

61. Qu Y, Aluisio L, Lord B, Boggs J, Hoey K, Mazur C, Lovenberg T: Pharmacokinetics and pharmacodynamics of norfluoxetine in rats: increasing extracellular serotonin level in the frontal cortex. Pharmacol. Biochem. Behav. 92(3), 469-473 (2009)

62. Rechtschaffen A, Bergmann BM: Sleep stage priorities in rebounds from sleep deprivation: a response to Feinberg. Sleep 22(8), 1025-1030 (1999)

63. Rechtschaffen A, Bergmann BM, Gilliland MA, Bauer K: Effects of method, duration, and sleep stage on rebounds from sleep deprivation in the rat. Sleep 22(1), 11-31 (1999)

64. Rechtschaffen A, Gilliland MA, Bergmann BM, Winter JB: Physiological correlates of prolonged sleep deprivation in rats. Science 221(4606), 182-184 (1983)

65. Robert C, Guilpin C, Limoge A: Automated sleep staging systems in rats. J. Neurosci. Methods 88(2), 111-122 (1999)

66. Rotiroti D, Silvestri R, de Sarro GB, Bagetta G, Nistico G: Evidence that behavioural and electrocortical sleep induced by guanfacine is due to stimulation of alpha 2-adrenoceptors. J. Psychiatr. Res. 17(3), 231-239 (1982)

67. Ruigt GS, Van Proosdij JN, Van Delft AM: A large scale, high resolution, automated system for rat sleep staging. I. Methodology and technical aspects. Electroencephalogr. Clin. Neurophysiol. 73, 52-63 (1989) 
68. Samuels ER, Szabadi E: Functional neuroanatomy of the noradrenergic locus coeruleus: its roles in the regulation of arousal and autonomic function part II: physiological and pharmacological manipulations and pathological alterations of locus coeruleus activity in humans. Curr. Neuropharmacol. 6(3), 254-285 (2008)

69. Sara SJ, Bouret S: Orienting and reorienting: the locus coeruleus mediates cognition through arousal. Neuron 76(1), 130-141 (2012)

70. Shoham S, Davenne D, Krueger JM: Muramyl dipeptide, amphetamine, and physostigmine: effects on sleep of rabbits. Physiol. Behav. 41(2), 179-185 (1987)

71. Sitaram N, Wyatt RJ, Dawson S, Gillin JC: REM sleep induction by physostigmine infusion during sleep. Science 191, 1281-1282 (1976)

72. Skinner DM, Overstreet DH, Orbach J: Reversal of the memory-disruptive effects of REM sleep deprivation by physostigmine. Behav. Biol. 18(2), 189-198 (1976)

73. Slater IH, Jones GT, Moore RA: Inhibition of REM sleep by fluoxetine, a specific inhibitor of serotonin uptake. Neuropharmacology 17(6), 383-389 (1978)

74. Steckler T, Inglis W, Winn P, Sahgal A: The pedunculopontine tegmental nucleus: a role in cognitive processes? Brain Res. Rev. 19(3), 298-318 (1994)

75. Tobler I, Borbely AA: The effect of 3-h and 6-h sleep deprivation on sleep and EEG spectra of the rat. Behav. Brain Res. 36(1-2), 73-78 (1990)

76. Tononi G, Cirelli C: Sleep function and synaptic homeostasis. Sleep Med. Rev. 10(1), 49-62 (2006)

77. Tóth A, Hajnik T, Záborszky L, Détári L: Effect of basal forebrain neuropeptide Y administration on sleep and spontaneous behavior in freely moving rats. Brain Res. Bull. 72(4-6), 293-301 (2007)

78. Trachsel L, Tobler I, Achermann P, Borbely AA: Sleep continuity and the REM-nonREM cycle in the rat under baseline conditions and after sleep deprivation. Physiol. Behav. 49(3), 575-580 (1991)

79. Trachsel L, Tobler I, Borbely AA: Effect of sleep deprivation on EEG slow wave activity within non-REM sleep episodes in the rat. Electroencephalogr. Clin. Neurophysiol. 73(2), 167-171 (1989)

80. Ursin R: Serotonin and sleep. Sleep Med. Rev. 6(1), 55-69 (2002)

81. Ursin R, Bjorvatn B, Sommerfelt L, Neckelmann D, Bjorkum AA: Studies on sleep/wake effects of serotonin reuptake inhibitors and receptor subtype involvement. J. Sleep Res. 1(3), 157-162 (1992)

82. Ursin R, Bjorvatn B, Sommerfelt L, Underland G: Increased waking as well as increased synchronization following administration of selective 5-HT uptake inhibitors to rats. Behav. Brain Res. 34(1-2), 117-130 (1989)

83. van Luijtelaar EL, Coenen AM: An EEG averaging technique for automated sleep-wake stage identification in the rat. Physiol. Behav. 33(5), 837-841 (1984)

84. Vanderwolf $\mathrm{CH}$ : Cerebral activity and behavior: control by central cholinergic and serotonergic systems. Int. Rev. Neurobiol. 30, 225-340 (1988)

85. Verge D, Calas A: Serotoninergic neurons and serotonin receptors: gains from cytochemical approaches. J. Chem. Neuroanat. 18(1-2), 41-56 (2000)

86. Vidal C, Changeux JP: Pharmacological profile of nicotinic acetylcholine receptors in the rat prefrontal cortex: an electrophysiological study in a slice preparation. Neuroscience 29(2), 261-270 (1989)

87. Vyazovskiy VV, Cirelli C, Tononi G: Electrophysiological correlates of sleep homeostasis in freely behaving rats. Prog. Brain Res. 193, 17-38 (2011)

88. Wenk H, Bigl V, Meyer V: Cholinergic projections from magnocellular nuclei of the basal forebrain to cortical areas in rats. Brain Res. Rev. 2, 295-316 (1980)

89. Woolf NJ: Cholinergic systems in mammalian brain and spinal cord. Prog. Neurobiol. 37(6), 475-524 (1991)

90. Yoshida M, Damsma G, Fibiger HC, Yokoo H, Mizoguchi K, Tanaka M: Central dopaminergic neurons: immunohistochemistry and in vivo monitoring of dopamine release correlated to behavior. Jpn. J. Psychiatry Neurol. 45(2), 525-528 (1991) 